\title{
Effect of Angiotensin-Converting Enzyme Inhibitor/Calcium Antagonist Combination Therapy on Renal Function in Hypertensive Patients With Chronic Kidney Disease: Chikushi Anti-Hypertension Trial - Benidipine and Perindopril
}

\author{
Tetsu Okuda ${ }^{a}$,, Keisuke Okamura ${ }^{a}$, Kazuyuki Shiraia ${ }^{a}$ \\ Hidenori Urata $^{\mathrm{a}}$
}

\begin{abstract}
Background: Appropriate blood pressure control suppresses progression of chronic kidney disease (CKD). If an angiotensin-converting enzyme (ACE) inhibitor is ineffective, adding a calcium antagonist is recommended. We compared the long-term effect of two ACE inhibitor/calcium antagonist combinations on renal function in hypertensive patients with CKD.

Methods: Patients who failed to achieve the target blood pressure (systolic/diastolic: $<130 / 80 \mathrm{~mm} \mathrm{Hg}$ ) with perindopril monotherapy were randomized to either combined therapy with perindopril and the L-type calcium antagonist amlodipine (group A) or perindopril and the T/L type calcium antagonist benidipine (group B). The primary endpoint was the change of the estimated glomerular filtration rate (eGFR) after 2 years. Eligible patients had a systolic pressure $\geq 130$ $\mathrm{mm} \mathrm{Hg}$ and/or diastolic pressure $\geq 80 \mathrm{~mm} \mathrm{Hg}$ and $\mathrm{CKD}$ (urine protein (+) or higher, eGFR $<60 \mathrm{~min} / \mathrm{mL} / 1.73 \mathrm{~m}^{2}$ ).
\end{abstract}

Results: After excluding 38 patients achieving the target blood pressure with perindopril monotherapy, 121 patients were analyzed (62 in group A and 59 in group B). Blood pressure decreased significantly in both groups, but there was no significant change of the eGFR. However, among patients with diabetes, eGFR unchanged in group $\mathrm{B}(\mathrm{n}=37,59.1 \pm 15.1$ vs. $61.2 \pm 27.9, \mathrm{P}=0.273)$, whereas decreased significantly in group $A(\mathrm{n}=31,57.3 \pm 16.0$ vs. $53.7 \pm 16.7, \mathrm{P}=$ $0.005)$.

Conclusions: In hypertensive patients with diabetic nephropathy, combined therapy with an ACE inhibitor and T/L type calcium antagonist may prevent deterioration of renal function more effectively than an ACE inhibitor/L type calcium antagonist combination.

Manuscript submitted November 4, 2017, accepted November 23, 2017

aDepartment of Cardiovascular Disease, Fukuoka University Chikushi Hospital, 1-1-1, Zokumyoin, Chikusino-shi, Fukuoka 818-8502, Japan

${ }^{b}$ Corresponding Author: Tetsu Okuda, Department of Cardiovascular Disease, Fukuoka University Chikushi Hospital, 1-1-1, Zokumyoin, Chikusino-shi, Fukuoka 818-8502, Japan. Email: okdmed99d@yahoo.co.jp

doi: https://doi.org/10.14740/jocmr3253w
Keywords: Amlodipine; Benidipine; Chronic kidney disease; Diabetes; Perindopril; Hypertension

\section{Introduction}

Many large-scale studies have demonstrated that appropriate control of blood pressure can suppress progression of chronic kidney disease (CKD) [1] and occurrence of cardiovascular complications [2]. In CKD patients, proteinuria and a decrease of the estimated glomerular filtration rate (eGFR) are risk factors for end-stage renal failure or cardiovascular disease (CVD). It has also been reported that the risk of adverse outcomes increases as the eGFR declines or as urinary protein excretion becomes higher [3,4].

Considering the suppression of proteinuria and preservation of renal function, first-line antihypertensive therapy for CKD patients with diabetes or proteinuria includes renin-angiotensin system (RAS) inhibitors.

However, polypharmacy is often needed in CKD patients to achieve the target blood pressure [1], with calcium (Ca) antagonists and diuretics being recommended for combination therapy. The ACCOMPLISH trial showed that the incidence of renal events was lower in patients treated with a long-acting $\mathrm{Ca}$ antagonist and an ACE inhibitor than in patients using a thiazide diuretic plus an ACE inhibitor [5].

Different $\mathrm{Ca}$ antagonists show differing effects on urine protein excretion when administered concomitantly with RAS inhibitors [6-8]. Ca antagonists that block T or $\mathrm{N}$ type Ca channels are recommended to decrease proteinuria. However, the influence of $\mathrm{Ca}$ antagonist channel selectivity on the eGFR has not been clarified and there are few trials examined in the long term [6-8].

Accordingly, we conducted a prospective, randomized, multicenter study in hypertensive patients with CKD to evaluate the long-term (2 years) effect on renal function of combined therapy with the ACE inhibitor perindopril (which has shown efficacy in many clinical studies $[9,10]$ ) and amlodipine (an L-type Ca antagonist) versus combined therapy with perindopril and benidipine (a T/L type Ca antagonist). 
Table 1. Patient Characteristics

\begin{tabular}{llll}
\hline & Amlopidine group $(\mathbf{n}=\mathbf{6 2})$ & Benidipine group $(\mathbf{n}=\mathbf{5 9 )}$ & P-value \\
\hline Gender (male/female) & $38 / 24$ & $37 / 21$ & $\mathrm{NS}$ \\
Age (years) & $68.9 \pm 10.2$ & $69.0 \pm 9.1$ & $\mathrm{NS}$ \\
BMI (kg/m²) & $25.4 \pm 3.7$ & $25.2 \pm 3.5$ & $\mathrm{NS}$ \\
Smoking (yes/past/no) & $15 / 19 / 28$ & $13 / 15 / 31$ & $\mathrm{NS}$ \\
Drinking (yes/no) & $43 / 37$ & $46 / 30$ & $\mathrm{NS}$ \\
Perindopril (mg/day) & $4.2 \pm 1.2$ & $4.2 \pm 0.9$ & $\mathrm{NS}$ \\
Complications (n (\%)) & $57(91)$ & $54(91)$ & $\mathrm{NS}$ \\
Diabetes mellitus (n (\%)) & $24(39)$ & $28(47)$ & $\mathrm{NS}$ \\
Dyslipidemia (n (\%)) & $33(53)$ & $31(52)$ & $\mathrm{NS}$ \\
Hyperuricemia (n (\%)) & $16(25)$ & $12(21)$ & $\mathrm{NS}$ \\
Coronary artery disease (n (\%)) & $10(16)$ & $11(19)$ & $\mathrm{NS}$ \\
Heart failure (n (\%)) & $9(10)$ & $14(16)$ & $\mathrm{NS}$ \\
Cerebrovascular disease (n (\%)) & $5(8)$ & $4(7)$ & $\mathrm{NS}$ \\
Renal failure (n (\%)) & $2(3)$ & $0(0)$ & $\mathrm{NS}$ \\
\hline
\end{tabular}

BMI: body mass index; Cr: creatinine; eGFR: estimated glomerular filtration rate.

\section{Patients and Methods}

\section{Patients}

This was a prospective, randomized, multicenter comparative study with a 2-year observation period in hypertensive patients with CKD. The long-term effects of perindopril/amlodipine therapy and perindopril/benidipine therapy were compared with regard to blood pressure, eGFR, urinary albumin excretion, and urine protein excretion (qualitative). Before enrolment, we fully explained the details of the study to the candidate patients, and obtained written informed consent. This study was conducted in compliance with the Declaration of Helsinki.

Eligible patients fitted the following enrolment criteria: 1) blood pressure $\geq 130 / 80 \mathrm{~mm} \mathrm{Hg}$ measured at the outpatient clinic, 2) qualitative urine protein $(1+)$ or higher or eGFR $<60 \mathrm{~min} / \mathrm{mL} / 1.73 \mathrm{~m}^{2}, 3$ ) age $\geq 20$ years, 4) outpatients (not hospitalized), and 5) patients who provided written informed consent.

Exclusion criteria were as follows: 1) sitting systolic blood pressure (SBP) $\geq 200 \mathrm{~mm} \mathrm{Hg}$ or diastolic blood pressure (DBP) $\geq 120 \mathrm{~mm} \mathrm{Hg}$ at enrolment, 2) secondary hypertension, 3) serious cerebrovascular disease/CVD requiring hospitalization (e.g., stroke, myocardial infarction) within the previous 6 months, 4) cardiac failure (class III or IV in the NYHA functional classification), 5) severe liver dysfunction (AST or ALT $\geq 100 \mathrm{IU} / \mathrm{L}$ ) or severe renal dysfunction (serum creatinine $\geq 2.0 \mathrm{mg} / \mathrm{dL}$ ), 6) malignant tumor or another serious disease with a poor prognosis, 7) women who were pregnant or possibly pregnant, 8) patients with contraindications for any of perindopril, amlodipine, or benidipine, and 9) patients who were unsuitable for enrolment due to another medical reason in the opinion of the attend- ing physician.

\section{Methods}

During the observation period, written informed consent was obtained from candidate subjects, their eligibility was confirmed, and they were enrolled in the preliminary study period. Treatment was changed to monotherapy with perindopril (4 mg/day). Blood pressure was measured at our outpatient clinic according to the JSH 2009 guideline and the target blood pressure was $<130 / 80 \mathrm{~mm} \mathrm{Hg}$ as specified in this guideline. Patients who achieved the target blood pressure with perindopril at $4 \mathrm{mg}$ /day were excluded from the main study. Patients who failed to achieve the target blood pressure after at least 4 weeks of treatment with perindopril were randomized (using a table of random numbers) to either the amlodipine group or the benidipine group by the central registration method.

Dose escalation was allowed up to the approved maximum dose when the target blood pressure was not achieved after addition of amlodipine or benidipine. Antihypertensive drugs other than RA inhibitors or $\mathrm{Ca}$ antagonists could be added if the target blood pressure was not achieved with the maximum dose of amlodipine or benidipine.

Discontinuation criteria were as follows: 1) patients who showed deterioration such as worsening of hypertension or complications, 2) patients who required significant modification of treatment due to an event, 3) patients in whom continuation of study treatment became difficult due to a serious adverse event, 4) patients who the investigator judged should not continue treatment, 5) patients who asked to discontinue the study, and 6) patients who changed hospital and could not continue the study.

The primary endpoint was the change of eGFR from base- 
Blood Pressure

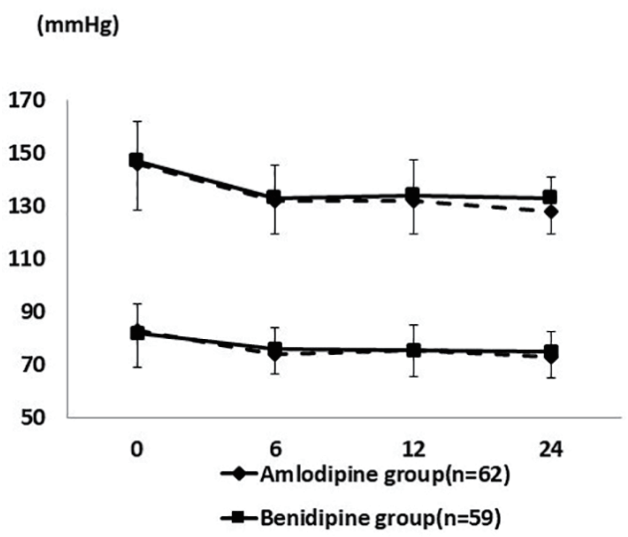

Heart Rate

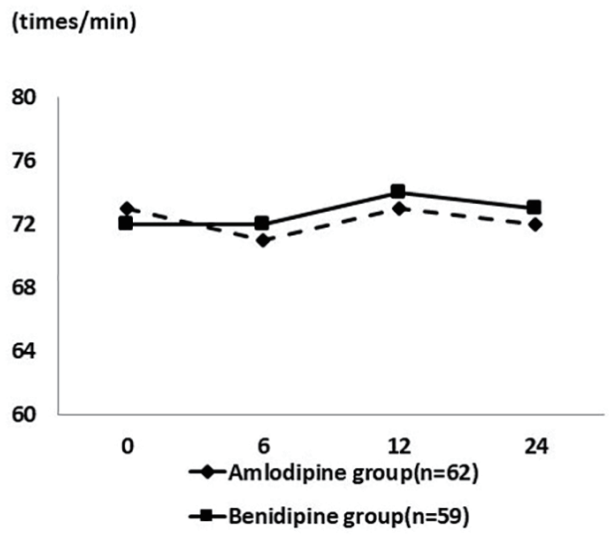

Figure 1. Changes of blood pressure and heart rate during the study period. Systolic and diastolic blood pressure decreased significantly in both groups. The heart rate remained at approximately the same level.

line to the end of the main study. Secondary endpoints were the change of CKD stage, change of urinary albumin excretion, and change of qualitative urine protein excretion. Laboratory tests were conducted at the time of obtaining informed consent, at enrolment in the main study, and 6, 12, and 24 months after the start of study treatment. Parameters assessed were the serum creatinine level, total cholesterol, triglycerides, highdensity lipoprotein (HDL) cholesterol, low-density lipoprotein (LDL) cholesterol, $\mathrm{Na}, \mathrm{K}$, and $\mathrm{Cl}$.

The eGFR was calculated by the revised abbreviated MDRD equation specified in the evidence-based clinical practice guideline for CKD 2013 [11]: eGFR (mL/min/1.73 $\left.\mathrm{m}^{2}\right)=194 \times($ age $)-0.287 \times($ serum $\mathrm{Cr})-1.094(\times 0.739$ for women).

\section{Statistical analysis}

Results are presented as the mean $\pm \mathrm{SD}$ or mean $\pm \mathrm{SE}$. Comparisons within or between groups were performed by the paired or unpaired $t$-test for data showing a normal distribution, and by the Wilcoxon test or Mann-Whitney test for other data. Categorical data were analyzed by the Chi-square test. Two-tailed $\mathrm{P}$ values $<0.05$ were accepted as indicating significance.

\section{Results}

\section{Study population and baseline characteristics}

A total of 214 patients were enrolled in the preliminary study. The 38 patients in whom the target blood pressure was achieved by perindopril monotherapy and 55 patients who met above discontinuation criteria were excluded from the main study, and the remaining 121 patients (62 in the amlodipine group and 59 in the benidipine group) were analyzed. Patient background factors at baseline are shown in Table 1. There were no significant differences of background factors between the two groups.

\section{Effect on blood pressure}

At the end of the study, the mean daily dose was $5.2 \pm 2.1 \mathrm{mg}$ for amlodipine and $5.3 \pm 2.1 \mathrm{mg}$ for benidipine. As shown in Figure 1, SBP and DBP decreased significantly from baseline after 6 months of treatment in both groups. SBP decreased from $145.8 \pm 18.8 \mathrm{~mm} \mathrm{Hg}$ to $128.2 \pm 13.8 \mathrm{~mm}$ $\mathrm{Hg}$ in the amlodipine group and from $146.7 \pm 15.6 \mathrm{~mm} \mathrm{Hg}$ to $133.5 \pm 12.9 \mathrm{~mm} \mathrm{Hg}$ in the benidipine group. The heart rate remained at approximately the same level throughout the study period.

\section{Effect on the eGFR}

As shown in Figure 2, there was no significant change of the mean eGFR. In the amlodipine group, mean eGFR was $57.8 \pm$ $17.2 \mathrm{~mL} / \mathrm{min} / 1.73 \mathrm{~m}^{2}$ at baseline and $56.2 \pm 19.3 \mathrm{~mL} / \mathrm{min} / 1.73$ $\mathrm{m}^{2}$ at the end of the study $(\mathrm{P}=0.113)$, while the respective values in the benidipine group were $58.2 \pm 14.4 \mathrm{~mL} / \mathrm{min} / 1.73$ $\mathrm{m}^{2}$ and $59.1 \pm 22.2 \mathrm{~mL} / \mathrm{min} / 1.73 \mathrm{~m}^{2}(\mathrm{P}=0.316)$. The change of eGFR showed no significant difference between the amlodipine group $\left(-1.58 \pm 10.1 \mathrm{~mL} / \mathrm{min} / 1.73 \mathrm{~m}^{2}\right)$ and the benidipine group $\left(0.83 \pm 13.2 \mathrm{~mL} / \mathrm{min} / 1.73 \mathrm{~m}^{2}\right)(\mathrm{P}=0.170)$.

As shown in Figure 3, the mean eGFR of patients with diabetes decreased significantly by the end of the study in the amlodipine group (from $57.3 \pm 16.0 \mathrm{~mL} / \mathrm{min} / 1.73 \mathrm{~m}^{2}$ to 53.7 $\left.\pm 16.7 \mathrm{~mL} / \mathrm{min} / 1.73 \mathrm{~m}^{2}, \mathrm{P}=0.005\right)$, but not in the benidipine group (from $59.1 \pm 27.9 \mathrm{~mL} / \mathrm{min} / 1.73 \mathrm{~m}^{2}$ to $61.2 \pm 37.9 \mathrm{~mL} /$ $\min / 1.73 \mathrm{~m}^{2}, \mathrm{P}=0.273$ ), indicating that renal function was better preserved in the benidipine group. However, the absolute change of eGFR did not show a significant difference between the amlodipine group and the benidipine group (-3.59 $\pm 6.2 \mathrm{~mL} / \mathrm{min} / 1.73 \mathrm{~m}^{2}$ vs. $2.08 \pm 17.7 \mathrm{~mL} / \mathrm{min} / 1.73 \mathrm{~m}^{2}, \mathrm{P}=$ 
Change of the mean eGFR

$\left(\mathrm{mL} / \mathrm{min} / 1.73 \mathrm{~m}^{2}\right)$

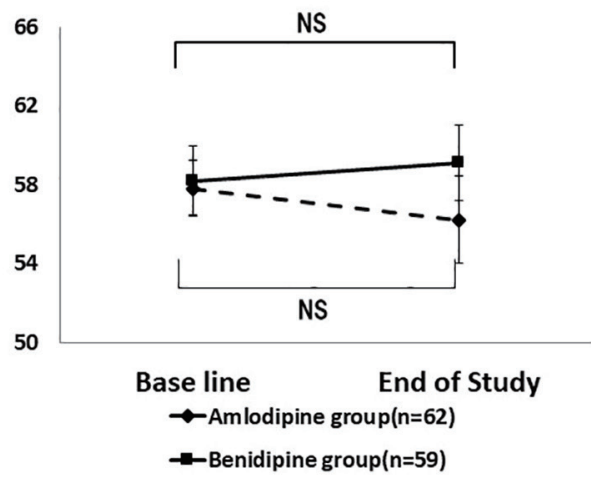

Change of eGFR

$\left(\mathrm{mL} / \mathrm{min} / 1.73 \mathrm{~m}^{2}\right)$

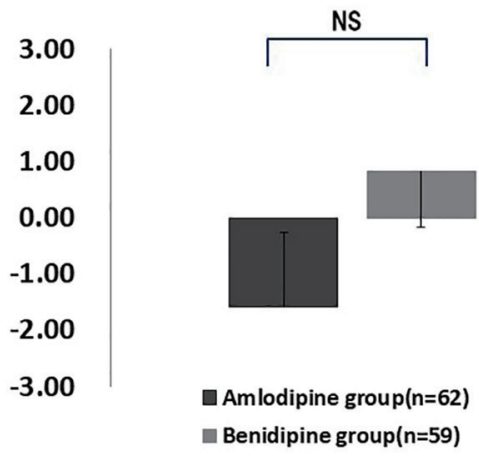

Figure 2. Changes of eGFR. There was no significant difference in the mean eGFR and the change of eGFR. NS: not significant.

Change of the mean eGFR

$\left(\mathrm{mL} / \mathrm{min} / 1.73 \mathrm{~m}^{2}\right)$

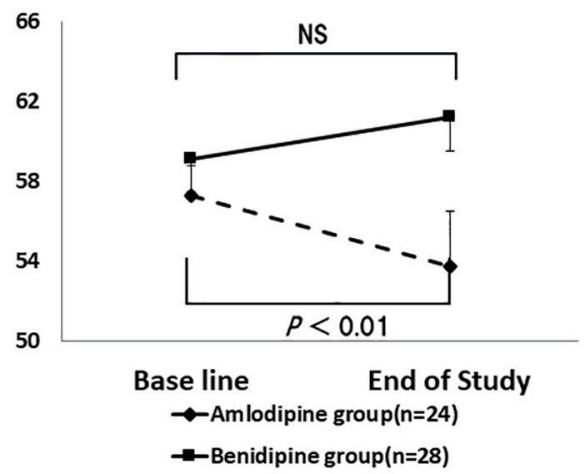

Change of eGFR

$\left(\mathrm{mL} / \mathrm{min} / 1.73 \mathrm{~m}^{2}\right)$

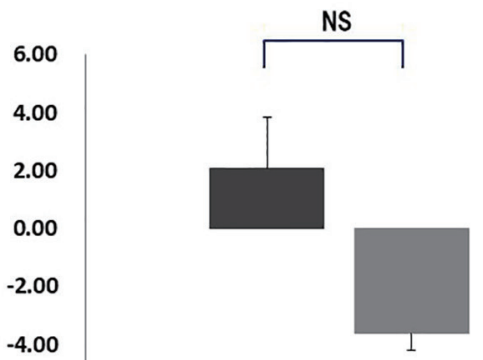

- Amlodipine group( $\mathrm{n}=24)$ Benidipine group $(\mathrm{n}=28)$

Figure 3. Changes of eGFR in diabetic patients. The mean eGFR decreased significantly in the amlodipine group, but not in the benidipine group. However, there was no significant difference in the change of eGFR. NS: not significant.

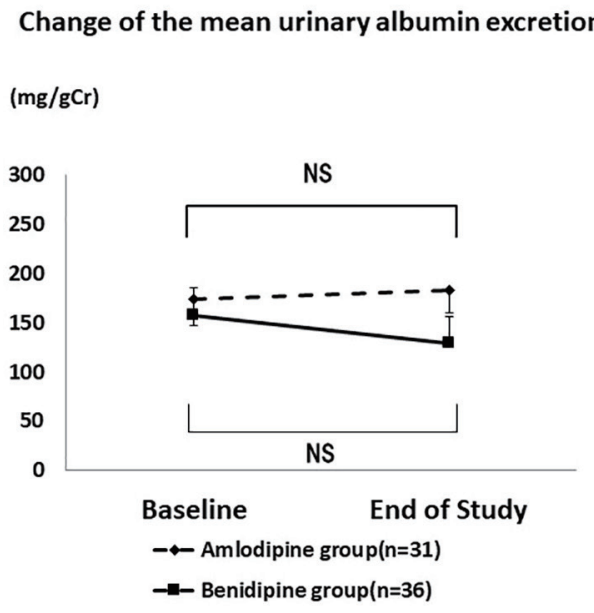

\section{Change of urinary albumin excretion}

$(\mathrm{mg} / \mathrm{gCr})$

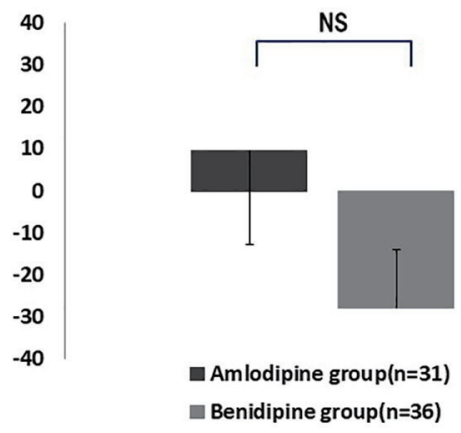

Figure 4. Changes of urinary albumin excretion. There was no significant difference in the mean urinary albumin excretion and the change of urinary albumin excretion. NS: not significant. 
( $\mathrm{mg} / \mathrm{gCr}$ )

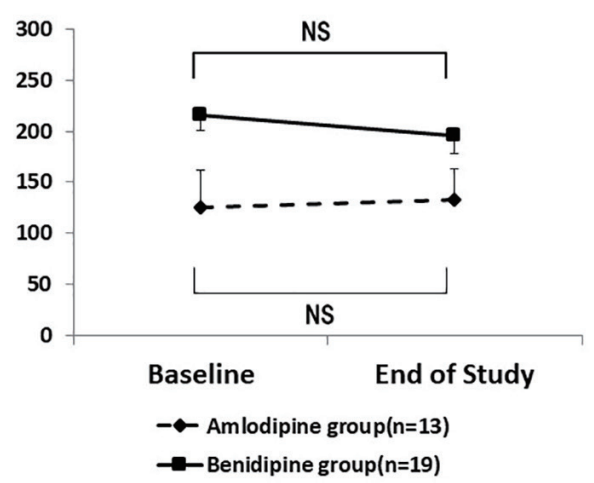

(mg/gCr)

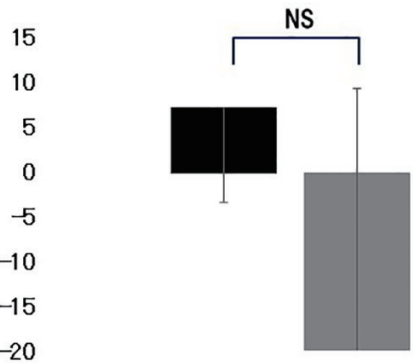

- Amlodipine group( $n=13)$ Benidipine group( $n=19$ )

Figure 5. Changes of urinary albumin excretion in diabetic patients. There was no significant difference in the mean urinary albumin excretion and the change of urinary albumin excretion in diabetic patients. NS: not significant.

$0.074)$.

\section{Urinary albumin excretion}

Mean urinary albumin excretion showed no significant changes during the study (Fig. 4). It was $174.0 \pm 288.9 \mathrm{mg} / \mathrm{gCr}$ at baseline and $183.4 \pm 272.8 \mathrm{mg} / \mathrm{gCr}$ at the end of the study $(\mathrm{P}$ $=0.356$ ) in the amlodipine group, while the respective values were $157.2 \pm 275.4 \mathrm{mg} / \mathrm{gCr}$ and $129.3 \pm 236.3 \mathrm{mg} / \mathrm{gCr}(\mathrm{P}=$ 0.231 ) in the benidipine group. The absolute change of urinary albumin excretion showed no significant difference between the amlodipine group and the benidipine group $(9.4 \pm 137.8$ $\mathrm{mg} / \mathrm{gCr}$ vs. $-27.9 \pm 221.5 \mathrm{mg} / \mathrm{gCr}, \mathrm{P}=0.214)$.

Mean urinary albumin excretion also showed no significant change in patients with diabetes (Fig. 5). It was $125.6 \pm$ $141.3 \mathrm{mg} / \mathrm{gCr}$ at baseline and $132.9 \pm 172.0 \mathrm{mg} / \mathrm{gCr}$ at the end of the study $(\mathrm{P}=0.408)$ in the amlodipine group, while the respective values in the benidipine group were $215.2 \pm 360.9$ $\mathrm{mg} / \mathrm{gCr}$ and $306.0 \pm 195.4 \mathrm{mg} / \mathrm{gCr}(\mathrm{P}=0.389)$. The absolute change of urinary albumin excretion also showed no significant difference between patients with diabetes in the amlodipine group and the benidipine group $(7.3 \pm 106.1 \mathrm{mg} / \mathrm{gCr}$ vs. $-19.8 \pm 292.1 \mathrm{mg} / \mathrm{gCr}, \mathrm{P}=0.379$ ).

\section{Qualitative urine protein excretion}

Qualitative urine protein excretion was significantly improved in the amlodipine group (Fig. 6). It was rated as (-) in 25 patients at baseline and in 33 patients at the end of the study period, while it was rated as $( \pm)$ in four and three patients, $(1+)$ in 10 and four patients, $(2+)$ in eight and eight patients, and $(3+)$ in two patients and one patient, respectively $(\mathrm{P}=0.023)$.

Qualitative urine protein excretion also improved significantly in the benidipine group (Fig. 6). It was rated as (-) in 25

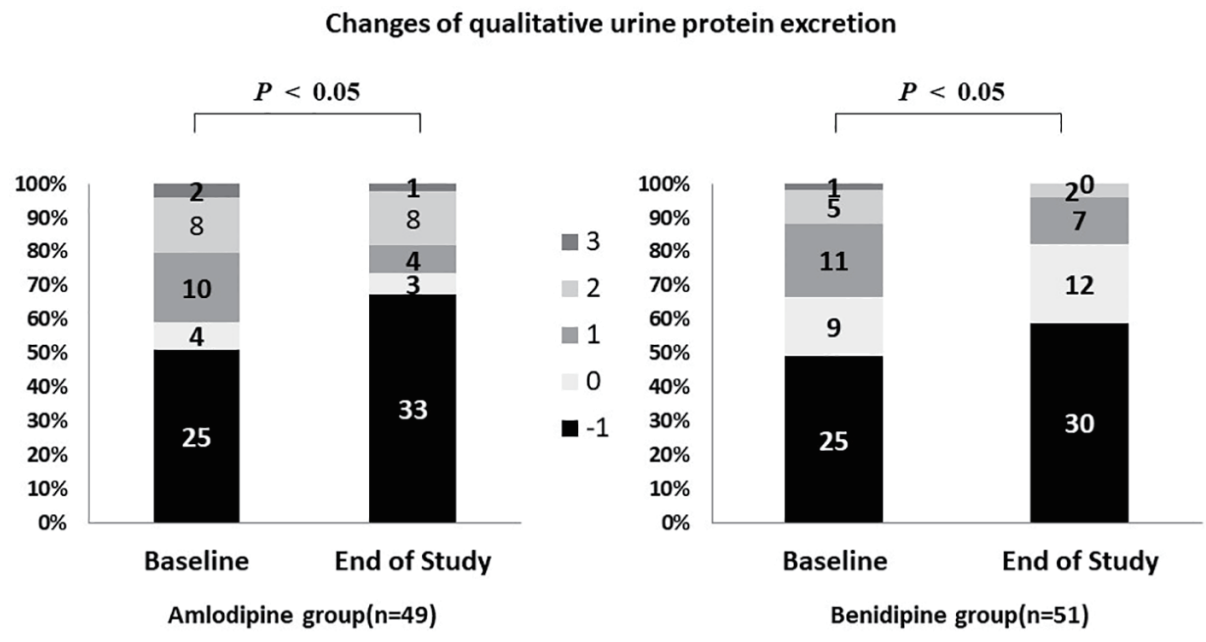

Figure 6. Changes of qualitative urine protein excretion. $\mathrm{P}<0.05$ vs. baseline. Qualitative urine protein excretion was significantly improved in both groups. 
patients at baseline and in 30 patients at the end of the study period, while it was rated as $( \pm)$ in nine and 12 patients, $(1+)$ in 11 and seven patients, $(2+)$ in five and two patients, and $(3+)$ in one and 0 patients, respectively $(\mathrm{P}=0.021)$.

\section{Discussion}

In the present study (Chikushi anti-hypertension trial - benidipine and perindopril (CHAT-BP)), the primary endpoint was eGFR, which increased in the benidipine group and decreased in the amlodipine group. However, there was no significant difference of eGFR between the two groups or between baseline and the end of the study within each group.

The small sample size of this study may be the primary reason for lack of a significant between-group difference. Although the target was to enroll 200 patients in each group, eGFR was evaluable in fewer than 50 patients per group. Only benidipine group showed a slight inprove, but not significant in the eGFR, suggesting that there may have been a significant difference between the benidipine and amlodipine groups if data had been obtained from more patients.

Recently, there has been an increase of patients with hypertension, diabetic nephropathy, and renal failure, and they account for the majority of patients starting dialysis in Japan. The objective of antihypertensive therapy is to reduce the blood pressure and suppress organ damage associated with hypertension, including renal failure [12].

A meta-analysis demonstrated a renoprotective effect of RAS inhibitors and superiority compared to other antihypertensive agents in hypertensive patients with diabetes [13]. Direct comparison between an angiotensin receptor blocker (ARB) and an ACE inhibitor (ONTARGET trial) did not show any significant difference in terms of preventing the progression of renal failure associated with hypertension [13].

Adverse reactions are less frequent with ARBs than ACE inhibitors (e.g., dry cough induced by the bradykinin-potentiating effect of ACE inhibitors), but ACE inhibitors are recommended as first-line therapy with/without $\mathrm{Ca}$ antagonists to reduce the cost of treatment $[14,15]$.

RAS inhibitors are the main agents for suppressing the progression of renal dysfunction associated with diabetes or hypertension. Drugs in this class dilate the efferent glomerular arterioles by suppressing angiotensin II and reduce the glomerular pressure, which in turn decreases proteinuria and prevents a decline of GFR [16]. It is important to lower the blood pressure and protect renal function by administration of RAS inhibitors at effective doses. However, these drugs tend to induce hyperkalemia or cause renal impairment, especially in patients with poor baseline renal function.

$\mathrm{Ca}$ antagonists are recommended for combination therapy with RAS inhibitors. These drugs are highly effective and economical, with no adverse effects on glucose metabolism, lipid metabolism, or electrolytes. Ca antagonists are useful in hypertensive patients with renal dysfunction or diabetes, who are prone to develop electrolyte abnormalities [17].

In Japan, amlodipine (an L-type $\mathrm{Ca}$ antagonist) and benidipine (an L/T type Ca antagonist) are frequently used with the aim of also preventing vasospastic angina [17]. Our present study suggested a renoprotective effect of benidipine compared to amlodipine in diabetic CKD patients with diabetes who had failed to respond to ACE inhibitor monotherapy. This result suggests that the efficacy of $\mathrm{Ca}$ antagonists for hypertensive patients with CKD or diabetes may be dependent on the Ca channel subtypes targeted by these drugs [18].

$\mathrm{Ca}$ antagonists target voltage-dependent calcium channels, which have several subunits with differing functions (classified as L-type, T-type, or N-type) that show different patterns of distribution in the kidney [18]. In the renal microvasculature, L-type Ca channels are only expressed in the afferent arterioles and not in the efferent arterioles, while T-type and N-type $\mathrm{Ca}$ channels are found in both afferent and efferent arterioles and in the nerve terminals regulating these arterioles. Differences in the distribution of different types of Ca channels may have an influence on glomerular pressure [18].

Many $\mathrm{Ca}$ antagonists are in clinical use and may show differing effect on the $\mathrm{Ca}$ channel subtypes. Representative $\mathrm{Ca}$ antagonists like nifedipine and amlodipine only act on L-type $\mathrm{Ca}$ channels, while benidipine acts on T-type $\mathrm{Ca}$ channels in addition to L-type Ca channels [19].

During progression of renal dysfunction, glomerular hypertension causes glomerulosclerosis, leading to an increase of proteinuria. L-type $\mathrm{Ca}$ antagonists may increase the glomerular pressure if the systemic blood pressure is not fully controlled, because L-type Ca channels are only expressed in the afferent arterioles. On the other hand, T-type Ca channels are expressed in both afferent and efferent arterioles. It has been reported that inhibition of T-type $\mathrm{Ca}$ channels dilates the afferent and efferent arterioles, alleviates glomerular hypertension [14], and prevents proteinuria and deterioration of GFR.

Inhibition of T-type $\mathrm{Ca}$ channels may also suppress renal fibrosis, since one of the characteristic effects of L/T-type $\mathrm{Ca}$ antagonists is stronger suppression of aldosterone production than L-type $\mathrm{Ca}$ antagonists and aldosterone is involved in renal fibrosis due to its effects on the renal vasculature.

Various hypotheses have been suggested to explain the progression of diabetic nephropathy, including RAS activation [12, 20]. Hyperglycemia and hyperinsulinemia increase the plasma aldosterone level. In CKD patients with diabetes, enhanced local RAS activity also increases aldosterone production and leads to contraction of the afferent and efferent arterioles, resulting in chronic hypoxia and inflammation in the kidney, as well as glomerular hypertension and angiopathy with exacerbation of renal dysfunction $[12,20]$.

T-type Ca channels are expressed in the zona glomerulosa of the adrenal cortex, which is the site of aldosterone production, and it was reported that L/T type $\mathrm{Ca}$ antagonists suppress aldosterone production. L-type $\mathrm{Ca}$ antagonists may increase proteinuria, while T-type $\mathrm{Ca}$ antagonists may show a renoprotective effect in diabetic patients due to anti-inflammatory activity and prevention of renal fibrosis by suppressing aldosterone production $[12,20]$.

Rho kinase may have a role in the mechanism by which benidipine suppresses the progression of renal dysfunction. Diabetic rats show increased Rho activity in the adrenal gland and enhanced urinary albumin excretion, which is suppressed 
by administration of a Rho kinase inhibitor. Activation of Rho/ Rho kinase in renal tissue induces overexpression of factors that promote fibrosis and progression of nephropathy [21]. In diabetes, the kidney is affected by chronic hypoxia and nonoxidative energy metabolism becomes predominant. Hypoxiainducible factor $1 \alpha(\mathrm{HIF} 1 \alpha)$ plays a central role in metabolism under hypoxic conditions. An increase of HIF $1 \alpha$ worsens renal impairment, while inhibition of Rho kinase facilitates degradation of HIF $1 \alpha$ and suppresses the progression of renal dysfunction [21].

In a rat model of diabetes, glomerular expression of Rho kinase is increased and benidipine reduces Rho kinase expression similar to Rho kinase inhibitors. Diabetic rats also show increased expression of Rock 1 mRNA, with Rho kinase inhibitors and benidipine suppressing its expression. Accordingly, benidipine may suppress Rho kinase activation and progression of diabetic nephropathy [22].

In the present study, we used an ACE inhibitor as basal therapy. Strict control of blood pressure is important in patients with diabetes and addition of a $\mathrm{Ca}$ antagonist is useful to achieve the target blood pressure. Dose escalation of the $\mathrm{Ca}$ antagonist rather than the RAS inhibitor may be a treatment option for poor blood pressure control, because $\mathrm{Ca}$ antagonists have a renoprotective effect while RAS inhibitors can worsen renal function or cause hyperkalemia.

Benidipine blocks the T-type Ca channel, lowers the glomerular pressure, and suppresses aldosterone production, making it suitable for treatment of diabetic nephropathy. Use of benidipine should be recommended for diabetic patients, because it is expected to show a superior organ-protective effect over amlodipine (and other L-type $\mathrm{Ca}$ antagonists) in addition to its antihypertensive effect.

\section{Conclusion}

The effects on renal function of the $\mathrm{Ca}$ antagonists amlodipine and benidipine were prospectively compared in hypertensive patients with CKD when these drugs were administered concomitantly with the ACE inhibitor perindopril. The primary endpoint (eGFR) showed no change in either group. However, among the patients with diabetes, eGFR decreased significantly in the amlodipine group, but did not change in the benidipine group.

This study showed that concomitant administration of an ACE inhibitor and benidipine (a T/L type $\mathrm{Ca}$ antagonist) in hypertensive patients with diabetic nephropathy may suppress deterioration of renal function compared to use of an ACE inhibitor and amlodipine (an L type Ca antagonist). These results suggest a renoprotective effect of benidipine in CKD patients with diabetes.

\section{Limitations}

The CHAT-BP study was performed in patients with relatively mild hypertension and the number of subjects analyzed was not large. In addition, we did not investigate the influence of different doses of benidipine or amlodipine, which may have biased the findings.

\section{Acknowledgments}

We thank members of Chikushi-JRN for recruiting patients to the study.

\section{Conflict of Interest}

The authors have received financial support from Kyowa Hakko Kirin Co., Ltd.

\section{References}

1. Bakris GL, Williams M, Dworkin L, Elliott WJ, Epstein $\mathrm{M}$, Toto $\mathrm{R}$, Tuttle $\mathrm{K}$, et al. Preserving renal function in adults with hypertension and diabetes: a consensus approach. National Kidney Foundation Hypertension and Diabetes Executive Committees Working Group. Am J Kidney Dis. 2000;36(3):646-661.

2. de Galan BE, Perkovic V, Ninomiya T, Pillai A, Patel A, Cass A, Neal B, et al. Lowering blood pressure reduces renal events in type 2 diabetes. J Am Soc Nephrol. 2009;20(4):883-892.

3. Nakayama M, Metoki H, Terawaki H, Ohkubo T, Kikuya M, Sato T, Nakayama K, et al. Kidney dysfunction as a risk factor for first symptomatic stroke events in a general Japanese population--the Ohasama study. Nephrol Dial Transplant. 2007;22(7):1910-1915.

4. Irie F, Iso H, Sairenchi T, Fukasawa N, Yamagishi K, Ikehara S, Kanashiki M, et al. The relationships of proteinuria, serum creatinine, glomerular filtration rate with cardiovascular disease mortality in Japanese general population. Kidney Int. 2006;69(7):1264-1271.

5. Bakris GL, Sarafidis PA, Weir MR, Dahlof B, Pitt B, Jamerson K, Velazquez EJ, et al. Renal outcomes with different fixed-dose combination therapies in patients with hypertension at high risk for cardiovascular events (ACCOMPLISH): a prespecified secondary analysis of a randomised controlled trial. Lancet. 2010;375(9721):1173-1181.

6. Fujita T, Ando K, Nishimura H, Ideura T, Yasuda G, Isshiki M, Takahashi K, et al. Antiproteinuric effect of the calcium channel blocker cilnidipine added to renin-angiotensin inhibition in hypertensive patients with chronic renal disease. Kidney Int. 2007;72(12):1543-1549.

7. Abe M, Okada K, Maruyama N, Matsumoto S, Maruyama T, Fujita T, Matsumoto K, et al. Benidipine reduces albuminuria and plasma aldosterone in mild-to-moderate stage chronic kidney disease with albuminuria. Hypertens Res. 2011;34(2):268-273.

8. Ogawa S, Mori T, Nako K, Ito S. Combination therapy with renin-angiotensin system inhibitors and the calcium channel blocker azelnidipine decreases plasma inflammatory markers and urinary oxidative stress markers 
in patients with diabetic nephropathy. Hypertens Res. 2008;31(6):1147-1155.

9. Patel A, Group AC, MacMahon S, Chalmers J, Neal B, Woodward M, Billot L, et al. Effects of a fixed combination of perindopril and indapamide on macrovascular and microvascular outcomes in patients with type 2 diabetes mellitus (the ADVANCE trial): a randomised controlled trial. Lancet. 2007;370(9590):829-840.

10. Beckett NS, Peters R, Fletcher AE, Staessen JA, Liu L, Dumitrascu D, Stoyanovsky V, et al. Treatment of hypertension in patients 80 years of age or older. N Engl J Med. 2008;358(18):1887-1898.

11. Kimura K, et al. Evidence-based Clinical Practice Guideline for CKD. Japanese Society of Nephrology. 2013; xiv.

12. Akizuki O, Inayoshi A, Kitayama T, Yao K, Shirakura S, Sasaki K, Kusaka H, et al. Blockade of T-type voltage-dependent $\mathrm{Ca} 2+$ channels by benidipine, a dihydropyridine calcium channel blocker, inhibits aldosterone production in human adrenocortical cell line NCI-H295R. Eur J Pharmacol. 2008;584(2-3):424-434.

13. Barnett AH, Bain SC, Bouter P, Karlberg B, Madsbad S, Jervell J, Mustonen J, et al. Angiotensin-receptor blockade versus converting-enzyme inhibition in type 2 diabetes and nephropathy. N Engl J Med. 2004;351(19):19521961.

14. Wu HY, Huang JW, Lin HJ, Liao WC, Peng YS, Hung $\mathrm{KY}, \mathrm{Wu} \mathrm{KD}$, et al. Comparative effectiveness of reninangiotensin system blockers and other antihypertensive drugs in patients with diabetes: systematic review and bayesian network meta-analysis. BMJ. 2013;347:f6008.

15. Pitt B, Poole-Wilson PA, Segal R, Martinez FA, Dickstein K, Camm AJ, Konstam MA, et al. Effect of losartan compared with captopril on mortality in patients with symptomatic heart failure: randomised trial - the
Losartan Heart Failure Survival Study ELITE II. Lancet. 2000;355(9215):1582-1587.

16. Lewis EJ, Hunsicker LG, Bain RP, Rohde RD. The effect of angiotensin-converting-enzyme inhibition on diabetic nephropathy. The Collaborative Study Group. N Engl J Med. 1993;329(20):1456-1462.

17. Mancia G, Laurent S, Agabiti-Rosei E, Ambrosioni E, Burnier M, Caulfield MJ, Cifkova R, et al. Reappraisal of European guidelines on hypertension management: a European Society of Hypertension Task Force document. J Hypertens. 2009;27(11):2121-2158.

18. Hayashi K, Homma K, Wakino S, Tokuyama H, Sugano N, Saruta T, Itoh H. T-type Ca channel blockade as a determinant of kidney protection. Keio J Med. 2010;59(3):8495.

19. Furukawa T, Nukada T, Namiki Y, Miyashita Y, Hatsuno K, Ueno Y, Yamakawa T, et al. Five different profiles of dihydropyridines in blocking T-type $\mathrm{Ca}(2+)$ channel subtypes $(\mathrm{Ca}(\mathrm{v}) 3.1$ (alpha(1G)), $\mathrm{Ca}(\mathrm{v}) 3.2$ (alpha(1H)), and $\mathrm{Ca}(\mathrm{v}) 3.3$ (alpha(1I))) expressed in Xenopus oocytes. Eur J Pharmacol. 2009;613(1-3):100-107.

20. Isaka $\mathrm{T}$, Ikeda $\mathrm{K}$, Takada $\mathrm{Y}$, Inada $\mathrm{Y}$, Tojo $\mathrm{K}$, Tajima N. Azelnidipine inhibits aldosterone synthesis and secretion in human adrenocortical cell line NCI-H295R. Eur J Pharmacol. 2009;605(1-3):49-52.

21. $\mathrm{Wu} \mathrm{G}, \mathrm{Xu} \mathrm{M}, \mathrm{Xu} \mathrm{K}, \mathrm{Hu}$ Y. Benidipine protects kidney through inhibiting ROCK1 activity and reducing the epithelium-mesenchymal transdifferentiation in type 1 diabetic rats. J Diabetes Res. 2013;2013:174526.

22. Sugano N, Wakino S, Kanda T, Tatematsu S, Homma K, Yoshioka K, Hasegawa K, et al. T-type calcium channel blockade as a therapeutic strategy against renal injury in rats with subtotal nephrectomy. Kidney Int. 2008;73(7):826-834. 